\title{
Analysis of supply chain principal-agent incentive contract
}

\author{
Guohong Shi*, Zhiwang Qian, Danqin Zhang \\ School of Business Administration, Jiangsu University, Zhenjiang, Jiangsu 212013, P.R.China
}

(Received December 23 2006, Accepted March 5 2006)

\begin{abstract}
To a large extent, the effort coefficient of retailer determines the market demand in supply chain. Nevertheless, because of asymmetric information, suppliers can not observe the real behaviors of retailer. Furthermore, it influences the expected returns of supplier and the balance of supply chain. Using the principalagency theory of Information Economics and comparing the linear contract under asymmetric information and symmetric information, this article has conducted a further research on the impact on the establishment of incentive contract mechanism of two-layer supply chain (including one supplier and one retailer), analyzing the parameters such as external uncertainty 's effect on the reward rate, the effort coefficient, fixed income, the expected income of the supplies, the real income of retailer and the agency cost.
\end{abstract}

Keywords: effort coefficient, principal-agent, asymmetric information, moral hazard

\section{Introduction}

In 2005 ten key questions which high administration had to face to in supply chain involve deep-level cooperation established between partnerships. So the upstream and downstream enterprises in supply chain must strengthen the cooperation, and establish effective prompting and measure mechanism to enhance the chain's executive effect. Thus it can be seen that prompting issue between upstream and downstream enterprises has aroused widespread attention in supply chain.

The principal-agent model between supplier and retailer is a bilateral moral hazard model including typical hidden behavior. According to the principal-agent theory of Nobel economic prize winner Morris, the client cannot observe the agent's behavior, such as the level of effort degree, ability, risk size, risk manner and so on. The agent maybe uses his own information superiority to maximize his self-effectiveness by reducing the effort level, because asymmetrical information and uncertainty exist at the same time. In the principalagent model, the action variable is effort level, which is expressed as effort coefficient in this paper. In this typical principal-agent relationship, the supplier can't observe the retailer's effort level absolutely. So the retailer will have the moral risk making use of the non-observability of the effort degree. Therefore, in order to promote the retailer to devote more endeavors what the supplier wants, it is necessary for the supplier to establish effective promoting contract.

The principal-agent issue is caused by the asymmetric information. In supply chain system, inconsistent goals between the overall system and local interest induce the reduction of the performance of the entire supply chain. By providing appropriate information and promoting measure, the supply chain contract can guarantee the bilateral coordination between supplier and retailer, optimizing the marketing channel performance and making the supply chain to achieve the best coordination.

In this paper, by principal-agent theory in the information economics, we study the principal-agent issue between the supplier and retailer under the asymmetric information (supplier is client, retailer is agent). For the supplier, he only can observe the sales quantity in the market, but can not observe the retailer's effort

\footnotetext{
* E-mail address: shi-guohong@ sina.com.
} 
specifically (this paper supposes the retailer's highest level effort and the lowest level effort which is known, according to the experience or the comparison in the same industry). In this situation, the asymmetrical information is caused, and subsequently adverse select and moral risks are caused. Adverse select is the asymmetrical information model which studies the game between the participants beforehand, but the moral risk is the asymmetrical information model which studies the game between the participants afterwards ${ }^{[9]}$. From the information economics' perspective. [7, 8] have analyzed contractual relationship between the client and agent thoroughly. By the differ of retailer's effort level, [5] analyzes the establishment of promoting contract under the situation of symmetrical information and asymmetrical information. Starting from the effort coefficient, this paper analyses the principal-agent model between supplier and retailer, using the effort coefficient what is linear representative of the highest effort level and the lowest effort level, which is more representative and comparative. So it can analyze the influence of the highest-level effort and the lowest-level effort towards the design of whole promoting contract. Comparing the situation of symmetrical information and asymmetrical information, this paper analyzes the influence of exterior uncertainty, retailer's risk loathing degree, retailer's ability coefficient, retailer's cost coefficient towards the return rate, the agent cost and the supplier's income. Designing an appropriate promoting contract is crucial for the coordination and the contract between supplier and retailer.

\section{Basic framework}

This model is a stackelberg gambling which is composed of supplier $S$ and retailer $R$. As the client, the supplier is at the leader's position. But the retailer is the agent. The supplier provides the product to the retailer at $\operatorname{cost} c$, and the retailer sells the product by price $P$ in the market. But product sales quantity $Q$ is influenced by exterior uncertainty, the retailer's promotion effort level and the market random factors. The expression is

$$
\begin{aligned}
& Q=A \times f(e)+B+\theta \\
& e=\mu e^{H}+(1-\mu) e^{L}=\mu\left(e^{H}-e^{L}\right)+e^{L}
\end{aligned}
$$

Among them, $Q$ expresses sales quantity; $A$ expresses retailer's ability coefficient; $B$ indicates the local market condition which is a constant (generally speaking market condition is uncontrolled), and expressed by the fixed sales quantity; Random variable $\theta$ obeys normal distribution $\theta \sim N\left(0, \sigma^{2}\right) . f(e)$ is output function of effort level $e\left(e=\mu e^{H}+(1-\mu) e^{L}=\mu\left(e^{H}-e^{L}\right)+e^{L}\right)$. The retail's effort level is determined by effort coefficient. $e^{H}$ is retailer's the highest effort level. $e^{L}$ is retailer's the lowest effort level (supposing retailer's the highest effort level and the lowest effort level can forecast or is known); $\mu$ expresses the retailer's effort coefficient. If $\mu$ equal to 1 , it shows that retailer makes his highest level effort. If $\mu$ equal to 0 , it shows that retailer makes his lowest level effort. The expression $f^{\prime}(e)>0$ shows that the bigger retailer's effort coefficient is, the bigger sales quantity. The expression $f^{\prime \prime}(e) \leq 0$ shows that the bigger retailer's effort coefficient is, the smaller sales quantity. So increases speed of sales quantity reduced.

Fig. 1 the relationship between effort coefficient and effort level

Fig. 1 shows the relationship between effort coefficient and effort level. When the gap between $e^{H}$ and $e^{L}$ is bigger, we can get a bigger effort level under the condition of the same effort coefficient.

Supposing $c(e)$ is the cost of retailer $\left(c^{\prime}(e)>0, c^{\prime \prime}(e) \geq 0\right)$. In order to simplify our analyses, we suppose that $f(e)$ equal to $e$. The expression $f(e)=\mu e^{H}-(1-\mu) e^{L}$ shows that the sales quantity is linear function of effort level. $Q=A e+B+\theta=A\left(\mu e^{H}+(1-\mu) e^{L}\right)+B+\theta, c(e)=\frac{b e^{2}}{2}=\frac{b\left(\mu e^{H}+(1-\mu) e^{L}\right)^{2}}{2} . b$ is cost coefficient $(b>0)$.

The expression $c\left(e^{H}\right)>c\left(e^{L}\right)$ shows that the negative effectiveness of retailer's hard working is bigger than that of careless working. So the cost of hard working is bigger than careless working. If supply chain needs lower effort level, there is no moral risk exist. Supplier only needs to give the retail ration $\alpha$. Under the condition of symmetrical information, in order to ensure the reservation effectiveness level $s$, Supplier gives the same payment. Therefore the retailer will choose $e^{L}$.

In a period of this supply chain, $w$ is unit profit of commodity. It is the gap between the market price $p$ and the unit cost $c$. According to the income $w Q$ after the retailer sells the product, the supplier gives the 


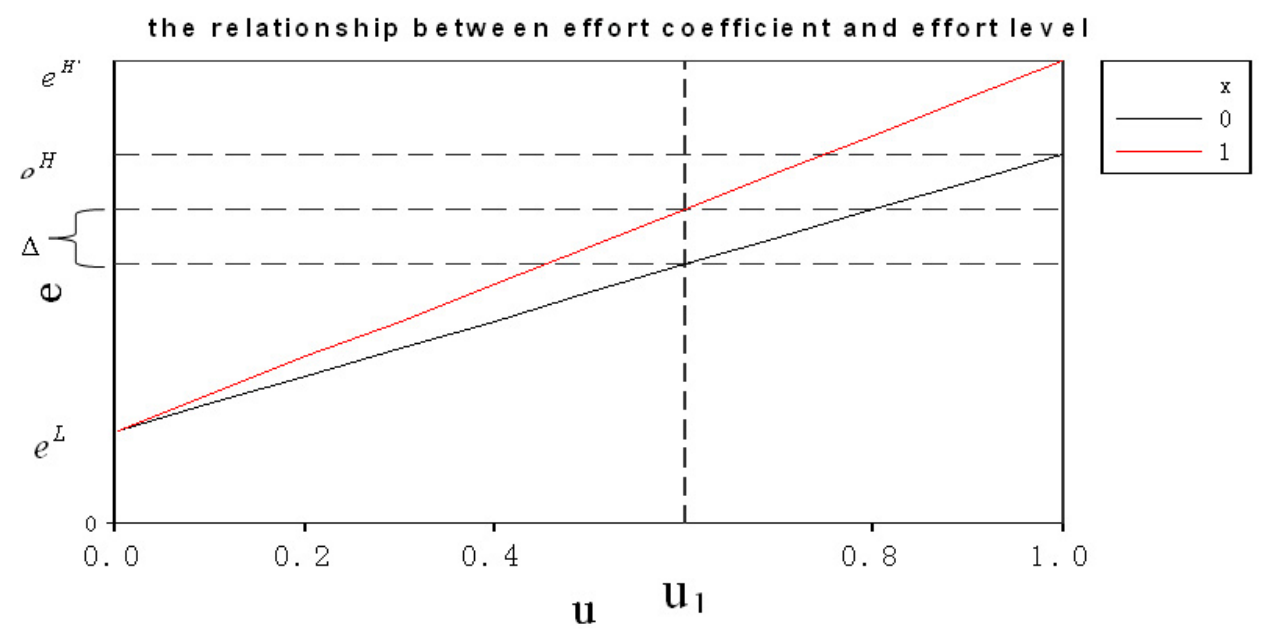

Fig. 1. The relationship between effort coefficient and effort level

retailer certain expense:

$$
s(Q)=\alpha+\beta w Q
$$

$s(Q)$ is the promoting contract which is the expense that supplier pays for retailer. $\alpha$ is fixed cost. $\beta$ is return rate which the retailer shares. Supposing supplier is risk-neutral. Its anticipant utility function is:

$$
\begin{aligned}
& E U(w Q-s(Q))=E(w Q-s(Q)) \\
& =(1-\beta) w(A e+B)-\alpha=(1-\beta) w\left\{A\left(\mu\left(e^{H}-e^{L}\right)+e^{L}\right)+B\right\}-\alpha
\end{aligned}
$$

Supposing the retailer is Risk-Averse, $V(X)=-e^{-r x}$ is utility function which is negative exponential utility function. $r$ is risk averse degree of retailer. If $r$ equals to 0 , it shows the retailer is Risk-Neutral. If $r$ is bigger than 0 , it shows the retailer is Risk-Averse. If $r$ is smaller than 0 , it shows the retailer is Risk-Love. The retailer's anticipant utility function is:

$$
E V(s(Q)-c(e))
$$

The retailer's fixed income is

$$
C E(\alpha, \beta)=\alpha+\beta w\left\{A\left(\mu\left(e^{H}-e^{L}\right)+e^{L}\right)+B\right\}-c(e)-\frac{1}{2} r \beta^{2} w^{2} \sigma^{2}
$$

When the supplier maximizes its own anticipant effectiveness, he will be restricted by the individual rational restriction and the incentive compatibility restraint of retailer. Thus, the principal-agent relationship between supplier and retailer can be expressed like the following model:

$$
\begin{gathered}
\text { (P) } \max (1-\beta) w\left\{A\left(\mu\left(e^{H}-e^{L}\right)+e^{L}\right)+B\right\}-\alpha \\
\text { s.t. } \quad e \in \arg \max \alpha+\beta w\left\{A\left(\mu\left(e^{H}-e^{L}\right)+e^{L}\right)+B\right\}-\frac{b\left(\mu e^{H}+(1-\mu) e^{L}\right)^{2}}{2}-\frac{1}{2} r \beta^{2} w^{2} \sigma^{2} \\
\alpha+\beta w\left\{A\left(\mu\left(e^{H}-e^{L}\right)+e^{L}\right)+B\right\}-\frac{b\left(\mu e^{H}+(1-\mu) e^{L}\right)^{2}}{2}-\frac{1}{2} r \beta^{2} w^{2} \sigma^{2} \geq \underline{s}
\end{gathered}
$$

Formula (8) is incentive compatibility restraint and formula (9) is individual rational restriction.

\section{Under the condition of symmetrical information}

Under the condition of symmetrical information, superior contract is that client gives complete insurance to agent. However, if the agent's effort can't be observed, once he has signed the contract, he will choose his favorable effort level. The reward given to agent does not lie on his effort, so he will make the lowest effort. 
Under the condition of symmetrical information, supplier can observe the effort level of retailer (effort coefficient is known). Incentive compatibility restraint is ineffective at this time. The individual rational condition comes into existence. Under the condition of symmetrical information, the model translates into:

$$
\begin{aligned}
& \text { (Q) } \max (1-\beta) w\left\{A\left(\mu\left(e^{H}-e^{L}\right)+e^{L}\right)+B\right\}-\alpha \\
& \text { s.t. } \quad \alpha+\beta w\left\{A\left(\mu\left(e^{H}-e^{L}\right)+e^{L}\right)+B\right\}-\frac{b\left(\mu e^{H}+(1-\mu) e^{L}\right)^{2}}{2}-\frac{1}{2} r \beta^{2} w^{2} \sigma^{2}=\underline{s}
\end{aligned}
$$

we can get from $(\mathbf{Q})$ :

$$
\left\{\begin{array}{l}
\mu^{*}=\frac{A w-e^{L} b}{b\left(e^{H}-e^{L}\right)} \\
\beta^{*}=0 \\
\alpha^{*}=\underline{s}+\frac{A^{2} w^{2}}{2 b}
\end{array}\right.
$$

The supplier's expected profit is:

$$
E U^{*}=\frac{A^{2} w^{2}}{2 b}+B w-\underline{s}
$$

and the retailer's real income is:

$$
s^{*}=\alpha^{*}+\beta^{*} w\left\{A\left(\mu^{*}\left(e^{H}-e^{L}\right)+e^{L}\right)+B\right\}=\underline{s}+\frac{A^{2} w^{2}}{2 b}
$$

\section{Under the condition of asymmetrical information}

Under the condition of asymmetrical information, the supplier cannot observe the retailer's effort level (i.e. effort coefficient is not known). Then Pareto-Efficiency cannot achieve.

According to

$$
\mu e^{H}+(1-\mu) e^{L}=\beta \frac{A w}{b}
$$

When there is no relationship between the expense which supplier pays for retailer and the retailer's sales quantity, the retailer will choose $e^{L}$.

In general, retailer's effort level is expressed by effort coefficient. It is difficult for supplier to observe. Under the condition of asymmetrical information, the model translates into:

$$
\begin{aligned}
& \text { (R) } \max (1-\beta) w\left\{A\left(\mu\left(e^{H}-e^{L}\right)-e^{L}\right)+B\right\}-\alpha \\
& \text { s.t. } \quad \alpha+\beta w\left\{A\left(\mu\left(e^{H}-e^{L}\right)-e^{L}\right)+B\right\}-\frac{b\left(\mu e^{H}-(1-\mu) e^{L}\right)^{2}}{2}-\frac{1}{2} r \beta^{2} w^{2} \sigma^{2} \geq \underline{s} \\
& \quad \mu=\frac{\beta \frac{A w}{b}-e^{L}}{\left(e^{H}-e^{L}\right)}
\end{aligned}
$$

we can get from $(\mathbf{R})$ :

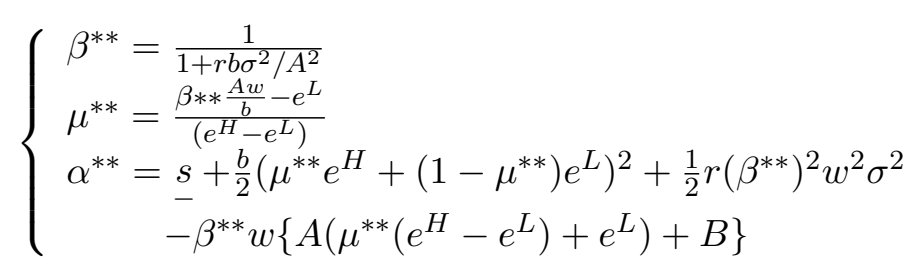

The supplier's expected profit is: 


$$
E U^{* *}=\left(1-\beta^{* *}\right) w\left\{A\left(\mu^{* *}\left(e^{H}-e^{L}\right)+e^{L}\right)+B\right\}-\alpha^{* *}=\frac{A^{2} w^{2}}{2 b\left(1+r b \sigma^{2} / A^{2}\right)}+w B-\underline{s}
$$

and the retailer's real income is:

$$
s^{* *}=\alpha^{* *}+\beta^{* *} w\left\{A\left(\mu^{* *}\left(e^{H}-e^{L}\right)+e^{L}\right)+B\right\}=\underline{s}+\frac{b}{2}\left(\mu^{* *}\left(e^{H}-e^{L}\right)+e^{L}\right)^{2}+\frac{1}{2} r\left(\beta^{* *}\right)^{2} w^{2} \sigma^{2}
$$

(1) Because $\beta^{* *}=\frac{1}{1+r b \sigma^{2} / A^{2}}$, we can get:

When $r=0, \beta=1, \mu^{*}=\frac{A w-e^{L} b}{b\left(e^{H}-e^{L}\right)}$, The retailer may achieve Pareto-Efficiency. When the retailer is Risk-Neutral, we can allow the retailer to undertake all risks and the profit property rights to inspire the retailer. Then the profit surplus property rights completely belong to the retailer. The supplier has given the retailer the property rights ${ }^{[5]}$. Because of $\frac{\partial \mu^{*}}{\partial A}=\frac{w}{b\left(e^{H}-e^{L}\right)}>0$, the bigger the retailer's ability coefficient is, the bigger the effort coefficient is; Because of $\frac{\partial \mu *}{\partial b}=-\frac{A w}{b^{2}\left(e^{H}-e^{L}\right)}<0$, the bigger the retailer's ability coefficient is, the smaller the effort coefficient is.

If $r>0$, along with the evadable coefficient $\mathrm{r}$ rises, the inspirit coefficient $\beta^{* *}$ correspondingly reduces. When risk evadable degree $r$ can counteract the inspirit functions of $\beta^{* *}$ (when $r \rightarrow \infty$, supplier undertakes all risks). The deeper the retailer's Risk-Averse is, the more inspirit (i.e. a higher return rate) needed to satisfy the retailer. Then the supplier undertakes a bigger risk. This is a balance question between Risk-Averse degree and inspirit in principal-agent problem.

(2) If $\frac{\partial E U^{* *}}{\partial A}>0, \frac{\partial E U * *}{\partial B}>0$, retailer's ability (A) is stronger, and market condition (B) is better, and then supplier's income higher. If $\frac{\partial E U^{* *}}{\partial r}<0, \frac{\partial E U^{* *}}{\partial b}<0$, retailer's Risk-Averse degree $(r)$ is stronger, and retailer's effort cost coefficient $(b)$ is bigger, and then supplier's income is lower.

(3) Generally speaking, when $\mu \geq 0.5$, namely retailer's effort level approaching the highest effort level. $\frac{A(p-c)-e^{L} b}{b\left(e^{H}-e^{L}\right)} \geq 0.5$ is supplier more likely to see.

When $A \geq \frac{b\left(e^{H}+e^{L}\right)}{2 w}, \beta \geq \frac{b^{2}\left(e^{H}+e^{L}\right)^{2}}{4 r b w^{2} \sigma^{2}+b^{2}\left(e^{H}+e^{L}\right)^{2}}$, it has certain limit to retailer's ability and the return rate that the supplier gives to the retailer.

(4) Under the condition of asymmetrical information, the risk cost that the retailer pay is $\frac{r w^{2} \sigma^{2}}{2\left(1+r b \sigma^{2} / A^{2}\right)^{2}}$. The retailer's effort cost saves $\frac{w^{2}\left(2 r \sigma^{2}+b r^{2} \sigma^{4} / A^{2}\right)}{2\left(1+r b \sigma^{2} / A^{2}\right)^{2}}$.

The supplier's agent cost is

$$
E U^{*}-E U^{* *}=\frac{A^{2} w^{2}}{2 b}+B w-\underline{s}-\left(\frac{A^{2} w^{2}}{2 b\left(1+r b \sigma^{2} / A^{2}\right)}+w B-s\right)=\frac{w^{2} \sigma^{2} r}{2\left(1+r b \sigma^{2} / A^{2}\right)}
$$

\section{Conclusion}

The contract design of supply chain has a significant effect on the coordination of supply chain. According to different conditions, suitable contract will be able to enhance the cooperation level. This paper studies the design of promoting mechanism. Supposing the retailer's highest level effort and the lowest effort level can be forecasted, we analyze the influence of some factors on the contact design such as the exterior uncertainty, retailer's risk loathing degree, retailer's ability coefficient and so on. It shows that we should design a promoting contract to enhance the retailer's effect coefficient. Under the condition of symmetrical information and asymmetrical information, this paper analyzes linear contract to conform effort coefficient, and the relationship between the effort coefficient and the return rate. Then we get some significant conclusions:

(1) Under the condition of symmetrical information, the retailer only need to pay certain fixed cost to the supplier; according to retailer's risk elusion degree and the cost coefficient, under the condition of asymmetrical information, the supplier can determine the return rate for retailer.

(2) Risk-Averse retailer is unable to achieve the Pareto-Efficiency. The supplier needs to pay the vicegerent cost.

(3) If supplier needs the retailer to be more diligent to enhance the retailer's effort coefficient, supplier needs to select retailers who have high ability coefficient and low cost coefficient. 
(4) The supplier chooses the retailer of high ability coefficient or market of good exterior condition to enhance its expectation income.

\section{References}

[1] T. Davis. Effective supply chain management. Sloan Management Review, 1993, 34(4): 35-46.

[2] M. Harris, A. Raviv. Optimal incentive contacts with imperfect information. Journal of Economic Theory, 1979, 2(3): 231-259.

[3] B. Houlihan. International supply chain management. International Journal of physical Distribution and material Management, 1987, 17(2): 51-66.

[4] H. Itoh. Collusion, incentives and risk sharing. Journal of Economic Theory, 1993, 60: 410-427.

[5] S. Li, D. Zhu. Principal-agent analysis of supply chain incentive contract with asymmetric information. CIMS, 2005, 1758-1762.

[6] E. Maskin, J. Riley. The principal-anent relationship with an informed principal, common value. Econometrica, 60(1): $1-42$.

[7] I. M. Stadler, J. D. Castrillo. An introduction to the Economics of Information Incentives and Contacts. Shanghai University of Finance \& Economics Press, 2004.

[8] L. Werin, H. Wijkander. Contract Economics. Economic Science Press, 1999.

[9] W. Zhang. Game Theory and Information Eeconomics, 1st edn. Shanghai People's Publishing House, 1996. 